\title{
Integrated conservation for Parakmeria omeiensis (Magnoliaceae), a Critically Endangered plant species endemic to south-west China
}

\author{
Daoping Yu, Xiangying Wen, Cehong Li, Tieyi Xiong, Qixin Peng \\ Xiajie Li, Kongring Xie, Hong Liu and Hai Ren
}

\begin{abstract}
Parakmeria omeiensis is a Critically Endangered tree species in the family Magnoliaceae, endemic to south-west China. The tree is functionally dioecious, but little is known about the species' status in the wild. We investigated the range, population size, age structure, habitat characteristics and threats to $P$. omeiensis. We located a total of 74 individuals in two populations on the steep slopes of Mount Emei, Sichuan province, growing under the canopy of evergreen broadleaved forest in well-drained gravel soil. A male-biased sex ratio, lack of effective pollinating insects, and habitat destruction result in low seed set and poor seedling survival in the wild. We have adopted an integrated conservation approach, including strengthening in situ conservation, cultivation of saplings, ex situ conservation and reintroduction, to protect this species. The successful conservation of $P$. omeiensis has important implications for the conservation of the genus Parakmeria and the family Magnoliaceae.
\end{abstract}

Keywords China, Critically Endangered species, cryptic dioecy, integrated conservation, Magnoliaceae, narrow distribution, Parakmeria omeiensis, reintroduction

\section{Introduction}

The tree species Parakmeria omeiensis (Magnoliaceae) is 1 endemic to south-west China. It was described as the type species of the genus Parakmeria (Hu \& Zheng, 1951). The earliest specimen was collected from Mount Emei in the city of Leshan in Sichuan province. Parakmeria omeiensis is evergreen, can reach $15^{-20} \mathrm{~m}$ in height and blooms from late April to mid May (Plate 1). The flowers are fragrant,

Daoping Yu*, Cehong Li, Tieyi Xiong, Qixin Peng, Xiaojie Li and Kongping Xie Sichuan Provincial Institute of Natural Resource Science, Chengdu, Sichuan, China, and Emeishan Botanical Garden, Emeishan, Sichuan, China

XIANGYING WEN ${ }^{*} \dagger$ and HaI ReN (Corresponding author, (D) orcid.org/0000-00023744-8007) Guangdong Provincial Key Laboratory of Applied Botany, South China Botanical Garden, Chinese Academy of Sciences, Guangzhou 510650, China. E-mail renhai@scbg.ac.cn

Hong LiU Department of Earth and Environment, International Center for Tropical Botany, Florida International University, Miami, USA

${ }^{*}$ Contributed equally

$\dagger$ Also at: Botanic Gardens Conservation International, Richmond, UK

Received 30 April 2019. Revision requested 15 July 2019.

Accepted 30 August 2019. First published online 9 June 2020. attractive and large, and their seed arils are orange, making the tree an attractive ornamental plant. However, the species has a restricted range. It has been considered a Grade-I Key-Protected Wild Plant Species in China since 1998 and has been categorized as Critically Endangered on the IUCN Red List since 2007 (China Expert Workshop, 2014), the Chinese Higher Plants Red List since 2013 (Yin, 2013), and the Red List of Magnoliaceae since 2016 (Malin et al., 2016). The tree has also been identified as a plant species with an extremely small population (Ren et al., 2012; State Forestry Administration of China, 2012).

Parakmeria includes five species ( $P$. nitita, $P$. lotungensis, P. kachirachirai, P. yunnanensis and P. omeiensis), distributed throughout south-east and south-west China. All species in the genus have male and perfect flowers on different plants and are thus morphologically androdiecious. The genus is considered to represent a transition from bisexual to unisexual flowers (Liu, 1984; Xu, 2002; Chen et al., 2011). Androdioecy is a rare breeding system in angiosperms (Listen et al., 1990; Fritsch \& Rieseberg, 1992; Pannell, 2002), and some studies have shown that androdiecious flowers are functionally dioecious (i.e. cryptic dioecious), with the morphologically perfect flowers being functionally female (Schlessman et al., 1990; Mayer \& Charlesworth, 1991; Sun et al., 2009). When the sex ratio of dioecious species is 1:1 in a population, it can maximize seed yield (Lloyd \& Webb, 1977), but sex ratio is often male-biased (Mayer \& Charlesworth, 1991).

The following factors have been suggested as threats to species of Parakmeria: habitat destruction, logging, a narrow range, low seed yields, low germination rates, and lack of protection (Xu, 2002; Deng et al., 2007). Improved knowledge of the pollination biology and breeding systems of the genus is required for developing conservation strategies. It has been suggested (Yu et al., 2011) that in situ conservation should be improved for threatened species with a cryptic dioecious breeding system, including monitoring plant survival and preventing human disturbance, and that these approaches should be coupled with ex situ conservation to maintain genetic diversity for potential reintroductions.

Individual $P$. omeiensis trees with perfect hermaphroditic flowers were first found on a steeply sloping ridge of Mount Emei at an altitude of $1,350 \mathrm{~m}$ (Wu \& Wu, 1989). We began to collect seeds from all fruiting female trees of the Biandanyan population during 1989-1993, germinating them at Emeishan Botanical Garden and obtaining 65 seedlings. The first 

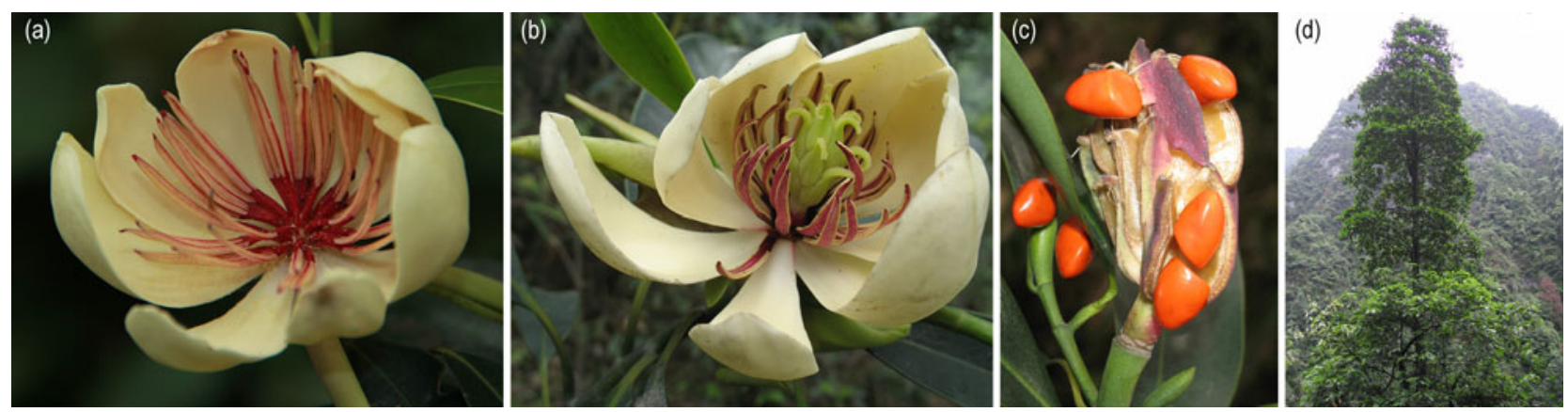

Plate 1 The flower (a, b), fruit (c) and an individual of Parakmeria omeiensis (d).

individual grew from seed to $18 \mathrm{~m}$ high and began flowering in May 2010. By 2018, 25 individuals had flowered.

Only preliminary studies have been conducted on the associated plant communities (Zhuang et al., 1993), tissue culture (Chen \& Ma, 2008; Yu et al., 2011) and breeding systems of P. omeiensis (Yu et al., 2019). Here we provide updated information on the species' range and population size, investigate population structure and threats to the species, and develop an integrated conservation strategy.

\section{Methods}

To identify the range of $P$. omeiensis, we reviewed the Flora of China (Xia et al., 2008) and other literature, and examined all specimens of the species in the herbaria of the Chinese Academy Sciences. We reassessed the populations based on data collected during 1985-2017, confirming that all known $P$. omeiensis are located on the north-east and north-west slopes of Mt Emei, in south-west Sichuan Province, China (Fig. 1).

During 2015-2017 we recorded the altitude, slope and soil type where the species is found. To investigate the size structure of $P$. omeiensis populations, we measured the height, diameter at breast height ( $\mathrm{DBH}$, for tree, height $>1.5 \mathrm{~m}$ ), and crown area of all plants located. We established three $10 \times 10 \mathrm{~m}$ plots to survey all tree species and five $2 \times 2 \mathrm{~m}$ subplots within each plot to survey shrubs and herbs. During 2015-2017 we interviewed eight local managers of the Mt Emei Scenic Spot and seven local villagers, to investigate any factors affecting the species.

In the flowering period (April-May) at Emeishan Botanical Garden during 2015-2017, flower visiting insects were caught and identified. We also carried out bagged pollination experiments using the ex situ population, to assess fruit-set from hand-pollination (cross-pollination with pollen from a male tree) and self-pollination. As a control treatment we used untreated flowers that were accessible to natural pollinators. We used 30 flowers for each treatment.

Seeds were collected from the Emeishan Botanical Garden in mid September 2015-2017, stored in a refrigerator for 6 months and sown in garden soil in March of each of the following years. We grafted P. omeiensis scions to rootstocks of
Magnolia denudata, from March 2014 to March 2018, as a propagation experiment. All seedlings were transplanted into nursery bags, with mixed humus and pearlites, at least 1 year before they were planted out. We carried out reintroductions (sensu IUCN, 2013) at two sites (Fig. 1): Zhanglaoping is within the known range of the species and Xixinsuo is close to the known range. We reintroduced both grafted female plants and seedlings of unknown sex. In March of each of 2016-2018, c. 500 individuals were outplanted into evergreen broadleaved forests at 1,200-1,550 m altitudes on Mt Emei.

\section{Results}

\section{Range and habitat}

From field surveys and herbarium studies during 2015-2017, we found only two populations, $2 \mathrm{~km}$ apart, at Biandanyan $\left(2 \mathrm{~km}^{2}\right)$ and Shisungou $\left(0.5 \mathrm{~km}^{2}\right)$, with a total of 145 associated vascular plant species (48 tree, 50 shrub, 44 herb and three vine species). The plant community is a subtropical evergreen broadleaved forest, with $85.6 \%$ of individual trees being evergreen. The climate is subtropical, with abundant rain and fog and warm, humid monsoons. The plant communities in the two areas are similar, dominated by species of the families Magnoliaceae and Lauraceae. The canopy is $18-25 \mathrm{~m}$ high, the plant community comprises one tree layer, one shrub layer and one herb layer, and plant cover was $70-80 \%$. Parakmeria omeiensis was scattered within the Michelia martini-Neolitsea levineiLithocarpus cleistocarpus-Sinarundinara nitida community at altitudes of $1,200-1,400 \mathrm{~m}$ on slopes of $50-75^{\circ}$. The average soil $\mathrm{pH}$ was 6.91 , and soil was well-drained gravel with $11.2 \%$ organic matter, $0.85 \%$ nitrogen and $0.1 \%$ phosphorus. We observed Near Threatened Tibetan rhesus monkeys Macaca thibetana frequently; they sometimes damaged branches and immature fruits of $P$. omeiensis.

\section{Population structure}

We found a total of 74 individuals of $P$. omeiensis in the two populations: 65 in Biandanyan, 22 of which flowered during 


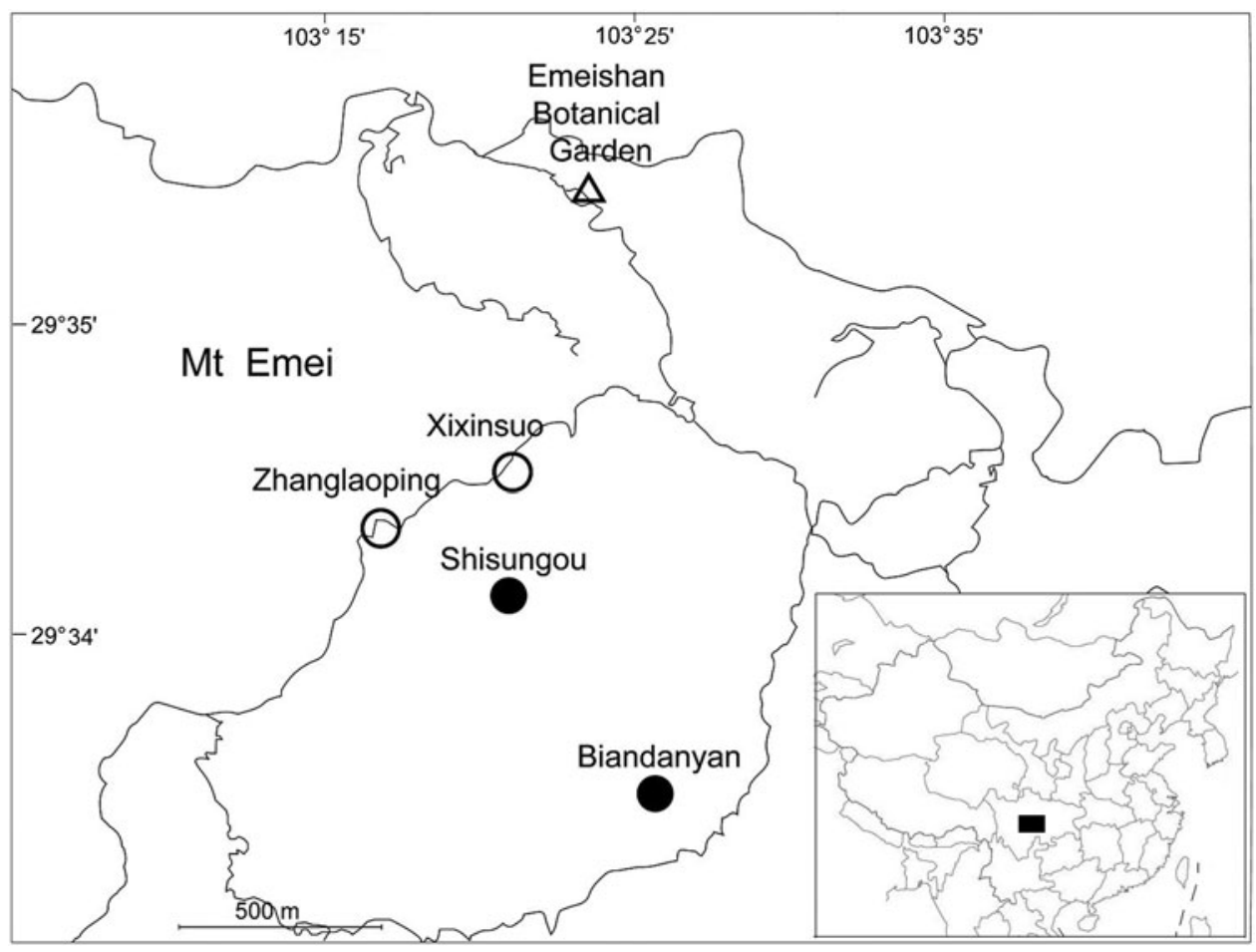

FIg. 1 The current distribution of Parakmeria omeiensis, showing the location of the two extant populations (at Shisungou and Biandanyan), the two reintroduction sites (Xixinsuo and Zhanglaoping) and the location of Emeishan Botanical Garden, where the species is cultivated. our fieldwork ( 16 male and 6 female trees, on the lower slopes and more sunny higher slopes, respectively), and nine in Shisungou, where only two male trees flowered and there were no individuals with perfect flowers (Fig. 1). The sex ratio of flowering individuals in Biandanyan was male-biased, with a ratio of 2.67 male: 1 female. We grouped the 74 individuals into seven size categories (Fig. 2), based on height for smaller individuals and DBH for larger individuals. Size structure was of the spindle type, indicating poor natural regeneration (Fig. 2).

\section{Conservation status}

In interviews, the local managers and villagers suggested that a narrow geographical range, a small area of occupancy, small population size, the low number of mature individuals, and fragmentation of the original population were major factors affecting the species. Based on our findings, we reassess the extinction risk (IUCN Standards and Petitions Subcommittee, 2019) for P. omeiensis as Endangered based on criteria $\mathrm{C}_{2} \mathrm{a}(\mathrm{i})$; i.e with $<2,500$ mature individuals $(\mathrm{C})$ and with a continuing decline inferred in numbers of mature individuals (2) and no subpopulation estimated to contain $>250$ mature individuals $(\mathrm{a}(\mathrm{i}))$. In addition, with $<5,000$ mature individuals in the wild and $<500$ in each isolated population, an extremely limited distribution range, pressures from habitat destruction, and occurrence in an area of high plant diversity and poor economic development ( $\mathrm{Yu}$ et al., 2011; Tao et al., 2020), $P$. omeiensis should continue to be considered as one of the Plant Species with Extremely Small Populations.

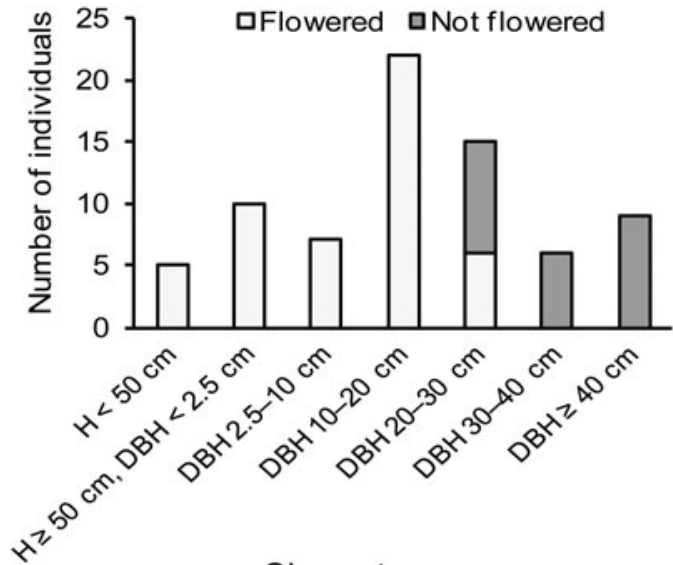

\section{Size category}

FIG. 2 The size structure ( $\mathrm{H}$, height; $\mathrm{DBH}$, diameter at breast height) of 74 P. omeiensis individuals in the wild.

\section{Pollination and grafting}

We found that hand-pollination increased fruit set compared to natural pollination. The mean fruit set of hand pollinated flowers was $93.3 \pm$ SE $4.4 \%$, with $14.9 \pm$ SE 1.2 seeds per fruit, nearly twice that of $46.7 \pm$ SE $4.4 \%$ fruit set and $6.93 \pm$ SE 0.9 seeds per fruit in the natural pollination. We observed six insect species (Apiscerana fabricius, Xylocopa sinensis, Haltica cyanea, Meligethes aeneus, Frankliniella intonsa, and Cecidomyiinae sp.) visiting flowers under natural conditions during informal observations, but only $M$. aeneus and $F$. intonsa are effective pollinators. The duration of stigma receptivity was short $(1.5-2 \mathrm{~h})$. There was little pollen on 
TABLE 1 Seed germination rate and growth of seedlings of Parakmeria omeiensis. The seeds were collected from Emeishan Botanical Garden and planted in the garden.

\begin{tabular}{llllll}
\hline Year & No. of seeds & No. that germinated & Germination rate $(\%)$ & $\begin{array}{l}\text { Mean height of } \\
\text { 1-year old seedlings }(\mathrm{cm})\end{array}$ & $\begin{array}{l}\text { Mean basal diameter of } \\
1 \text {-year old seedlings }(\mathrm{cm})\end{array}$ \\
\hline 2016 & 405 & 260 & 64.2 & 16.8 & 0.32 \\
2017 & 160 & 110 & 68.8 & 15.6 & 0.30 \\
2018 & 720 & 580 & 80.6 & 17.2 & 0.35 \\
\hline
\end{tabular}

TABLE 2 Survival rate and growth of grafted saplings.

\begin{tabular}{llllll}
\hline Date & Bud type & No. of grafts & No. surviving & Survival rate (\%) & Mean height of 1-year old saplings (cm) \\
\hline March 2016 & Axillary & 500 & 350 & 70.0 & 44.5 \\
April 2017 & Axillary & 440 & 240 & 54.5 & 37.8 \\
March 2018 & Terminal & 300 & 210 & 70.0 & 52.6 \\
\hline
\end{tabular}

TABLE 3 Survival rate and growth of transplanted saplings in three botanical gardens.

\begin{tabular}{lllllll}
\hline Location & $\begin{array}{l}\text { No. of } \\
\text { saplings }\end{array}$ & $\begin{array}{l}\text { No. } \\
\text { surviving }\end{array}$ & $\begin{array}{l}\text { Survival rate } \\
(\%)\end{array}$ & $\begin{array}{l}\text { Mean height } \\
(\mathrm{cm})\end{array}$ & $\begin{array}{l}\text { Mean basal diameter } \\
(\mathrm{cm})\end{array}$ & $\begin{array}{l}\text { Mean no. of } \\
\text { branches }\end{array}$ \\
\hline $\begin{array}{l}\text { Chengdu Botanical Garden } \\
\begin{array}{l}\text { West China Subalpine } \\
\quad \text { Botanical Garden }\end{array}\end{array}$ & 50 & 41 & 82.0 & 9.6 & 0.32 & 4.3 \\
$\begin{array}{l}\text { Kunming Botanical Garden } \\
\text { Kunming }\end{array}$ & 50 & 24 & 80.0 & 10.6 & 0.38 & 4.7 \\
\end{tabular}

TABLE 4 Survival rate and growth of saplings at reintroduction sites.

\begin{tabular}{llllllllr}
\hline Year & $\begin{array}{l}\text { Altitude } \\
(\mathrm{m})\end{array}$ & $\begin{array}{l}\text { No. of } \\
\text { saplings }\end{array}$ & $\begin{array}{l}\text { No. } \\
\text { surviving }\end{array}$ & $\begin{array}{l}\text { Survival rate } \\
(\%)\end{array}$ & $\begin{array}{l}\text { Mean height } \\
(\mathrm{cm})\end{array}$ & $\begin{array}{l}\text { Mean basal } \\
\text { diameter }(\mathrm{cm})\end{array}$ & $\begin{array}{l}\text { Mean crown } \\
\text { width }(\mathrm{cm})\end{array}$ & $\begin{array}{l}\text { Mean no. of } \\
\text { branches }\end{array}$ \\
\hline 2016 & $1,500-1,550$ & 120 & 93 & 77.5 & 92.7 & 1.31 & $52.6 \times 43.0$ & 9.9 \\
2017 & $1,300-1,350$ & 220 & 212 & 96.4 & 111.0 & 1.37 & $59.7 \times 50.4$ & 11.6 \\
2018 & $1,200-1,350$ & 160 & 154 & 96.3 & 106.5 & 1.34 & $55.4 \times 46.8$ & 10.7 \\
\hline
\end{tabular}

perfect flowers, and they did not germinate on the stigma. No fruit set from self-pollination treatments, indicating that pollen from the morphologically perfect flowers was not viable, rendering the trees that bear these flowers functionally female. The sexual system is xenogamous, and thus pollen must be collected from male plants for hand-pollination to ensure seed production. Of the 1,285 seeds collected during 2015-2017 from Emeishan Botanical Garden, a total of 950 seedlings were obtained (Table 1), and 580 of 800 grafted saplings were female (Table 2).

\section{Integrated conservation}

To protect $P$. omeiensis we used an integrated conservation strategy involving in situ and ex situ conservation, and reintroduction. The establishment of the Davidia involucrata Nature Reserve in 2005 within the range of $P$. omeiensis effectively protected the species habitat. The local Forest
Administration set up three patrol zones within the species' range, and we set up three camera traps (Onick, Wuhan, China) to monitor any disturbance. Together these monitoring efforts resulted in a decline from 12 thefts of plants in 2003 to none in 2017. We transferred 130 of the plants that we produced to three other Botanical Gardens (Table 3). The survival rate of plants in Chengdu Botanical Garden was lower than at the other two Botanical Gardens, mainly because of interference by tourists and the effects of heavy rainfall. Amongst the reintroduced plants, survival rate after 2 years was $96.4 \%$ at altitudes of $1,200-1,350 \mathrm{~m}$ and $77.5 \%$ at altitudes of $1,500-1,550 \mathrm{~m}$ (Table 4 ). We found that in 2016 the soil was so wet at the first site $(1,500-1,550 \mathrm{~m})$ that moss grew on the base of some saplings (soil water content reached 98.8\%). The moss inhibited soil aeration and resulted in the death of roots. Twenty-one saplings died as a result of these conditions. Six saplings planted by the roadside were killed by tourists, who broke branches. 


\section{Discussion}

Parakmeria omeiensis is a relict tree species of the $\mathrm{Pa}$ leotropical flora from the Tertiary period, with a narrow range. Our experimental results indicated that $P$. omeiensis is cryptically dioecious. It relies on outcrossing and the pollination services of insects to produce fruits and seeds but the required pollinating insects, at least in Emeishan Botanical Garden, are few, resulting in low fruit set. We also observed seeds destroyed by monkeys. We confirmed that the sex ratio of $P$. omeiensis is male biased. There is a tendency for male bias in tree species, limiting seed production (Sinclair et al., 2012). The uneven sex ratio may be the result of a number of factors, including human disturbance and environmental conditions such as nutrients, humidity, light and elevation. Environmental stresses induces maleness because female reproductive costs are higher than that of a male (Freeman et al., 1980). In addition, female trees tend to be less vigorous and more susceptible to environmental changes than male trees (Sun et al., 2009; Sinclair et al., 2012), which can result in a lower survival rate for female trees.

The climate of Mt Emei is changing, with ambient temperatures increasing and rainfall decreasing, especially in winter (Chen et al., 2010; Yu \& Liu, 2013). We have found that $P$. omeiensis seeds are underdeveloped and physiologically dormant at the time of dispersal (Yu et al., 2011), yet seeds need high water content during dormancy to maintain their viability. Climate change and reproductive challenges could put this species at a high risk of extinction; effective conservation will require intervention. Species with small population sizes are particularly susceptible to climate change (Rehnus et al., 2018) and an integrated conservation strategy is essential. As part of this, we increased the female:male plant ratio by grafting branches of known female plants and transplanting them into the wild. Reintroduction is an important way to reconstruct threatened plant populations (Liu et al., 2015; Ren, 2017), increase range and abundance, and reduce the risk of extinction (Liu et al., 2015; Sergei, 2018). Grafted female plants and seedlings grew well at altitudes of $1,200-1,350 \mathrm{~m}$. More than $90 \%$ of grafted plants developed new roots. However, some saplings at altitudes of 1,500-1,550 $\mathrm{m}$ died and the survival rate of this out-of-range introduction was lower than the other within range introduction. We will carry out further research on the effects of soils at the three sites on the growth of the species.

Although the current extant range of $P$. omeiensis is narrow, its potential ecological range is wider, as can be seen from the fact that it grows and develops normally in ex situ collections in southern China (Table 3). By translocating grafted plants and seedlings to locations both within and beyond the species' current range, we can help conserve the species in the face of climate change. We will also continue ex situ conservation efforts for this species in botanical gardens, to assist the ongoing conservation translocation efforts.

In summary, P. omeiensis is a Critically Endangered, cryptic dioecious plant endemic to south-west China. Threats to the species include a male biased sex ratio, poor natural regeneration, and climate change. We propose three principal conservation measures: hand-pollination, increasing female: male ratio by grafting and planting known female plants in reintroduced populations, and conducting ex situ conservation experiments in botanical gardens. The aims are to achieve a balanced sex ratio, increase the probability of seed set and seedling recruitment, and enable the species to respond to climate change. This integrated conservation approach could provide a reference for developing conservation strategies for other threatened, cryptic dioecious plant species.

Acknowledgements This research was supported by Botanic Garden Conservation International (Grant No. BGCI 30414) and Sichuan Science and Technology Department (Grant Nos 2017 SZ0090, 2017 YSKY0009, 2017TJPT0058). We thank the local forestry administration, staff from Chengdu Botanical Garden and West China Subalpine Botanical Garden, and local villagers for their participation in the conservation activities; Daojun Qi and Fujun Li for their help with fieldwork; Wanjun Zhang, Xunling Chen and Suqin Qi for monitoring outplanted saplings; and two anonymous reviewers for their constructive comments.

Author contributions Study design: DY, XW, HR; fieldwork: CL, DY, TX, QP, XL, KX, HR, XW; data analysis, writing: DY, XW, HL, HR.

\section{Conflicts of interest None.}

Ethical standards This research abided by the Oryx guidelines on ethical standards and was conducted under permits from Sichuan Provincial Institute of Natural Resource and Emeishan Forestry Administration. All intellectual property rights regarding data and results were managed within the legal requirements in China and were shared fairly among participants. Reintroduction experiments adopted the highest precautionary standards to avoid accidental introduction and distribution of invasive and pathogenic organisms, and followed IUCN/Species Survival Commission guidelines.

\section{References}

Chen, C., Pang, Y.M. \& Zhang, Y.F. (2010) Study on the characteristics of climate change in Sichuan basin in the recent 50 years. Journal of Southwest University, 32, 115-120.

Chen, H.F., Zhang, R.J., Zhou, J.S., XIng, F.W. \& Zeng, Q.W. (2011) Distribution and conservation strategy of Endangered Parakmeria lotungensis. Plant Science Journal, 29, 452-458.

Chen, Y. \& MA, M.D. (2008) Axillary bud and callus induction of stem segment Endangered plant of Parakmeria omeiensis. Forestry Science \& Technology, 33, 10-12.

China Expert Workshop (2014) Magnolia omeiensis. In The IUCN Red List of Threatened Species 2014: e. T34961A2857537. dx.doi.org/10. 2305/IUCN.UK.2014-1.RLTS.T34961A2857537.en [accessed 4 March 2020].

DenG, X.M., XI, R.C. \& FU, S.G. (2007) Establishment of highly efficient regeneration system of Parakmeria lotungensis. Acta Agriculturae University Jiangxiensis, 29, 189-202. 
Freeman, D.C., Harper, K.T. \& Charnov, E.L. (1980) Sex change in plants: old and new observations and new hypotheses. Oecologia, $47,1-11$.

Fritsch, P. \& Rieseber, L.H. (1992) High outcrossing rates maintain male and hermaphrodite individuals in populations of the flowering plant Datisca glomerata. Nature, 356, 633-636.

Hu, X.S. \& ZHENG, W.J. (1951) A new genus-Parakmeria Hu et Cheng of Magnoliaceae in the southwest of China. Acta Phytotaxon Sin, 1, 1-3.

IUCN (2007) Threats Authority File v. 2.1. iucnredlist.org/info/ major-threats [accessed 11 February 2020].

IUCN (2013) Guidelines for Reintroductions and Other Conservation Translocations. Version 1.o. IUCN, Gland, Switzerland.

IUCN Standards and Petitions Subcommittee (2019) Guidelines for Using the IUCN Red List Categories and Criteria v. 14 iucnredlist.org/documents/RedListGuidelines.pdf [accessed 15 March 2020].

Lloyd, D.G. \& WebB, C.J. (1977) Secondary sex characters in plants. Botanical Review, 43, 177-216.

Listen, A., Riesebergl, H. \& Elias, T.S. (1990) Functional androdioecy in the flowering plant Datisca glomerata. Nature, $343,641-642$.

LiU, H., Ren, H. \& LiU, Q. (2015) The conservation translocation of threatened plants as a conservation measure in China: a review. Conservation Biology, 29, 1537-1551.

LiU, Y.H. (1984) A preliminary study on the taxonomic system of Magnoliaceae. Acta Phytotaxon Sin, 22, 89-109.

Malin, R., Emily, B., Lydia, M. \& SARA, O. (2016) The Red List of Magnoliaceae. Revised and Extended. Botanic Gardens Conservation International, Richmond, UK.

Mayer, S.S. \& Charlesworth, D. (1991) Cryptic dioecy in flowering plants. Trends in Ecology \& Evolution 6, 320-325.

PANNelL, J.R. (2002) The evolution and maintenance of androdioecy. Annual Review of Ecology and Systematics, 33, 397-425.

Rehnus, M., Bollmann, K., Schmatz, D.R., Hackländer, K. \& Braunisch, V. (2018) Alpine glacial relict species losing out to climate change: the case of the fragmented mountain hare population (Lepus timidus) in the Alps. Global Change Biology, 24, 3236-3253.

REN, H. (2017) The role of botanical gardens in reintroduction of plants. Biodiversity Science, 25, 945-950.
Ren, H., ZhanG, Q.M. \& Lu, H.F. (2012) Wild plant species with extremely small populations require conservation and reintroduction in China. Ambio, 41, 913-917.

Schlessman, M.A., Lowry, Y.P.P. \& Lloyd, D.G. (1990) Functional dioecism in the New Caledonian endemic Polyscias pancheri (Araliaceae). Biotropica, 22, 133-139.

SERGEI, V. (2018) Securing a future for China's plant biodiversity through an integrated conservation approach. Plant Diversity, 40, 91-105.

Sinclair, J.P., Emlen, J. \& Freeman, D.C. (2012) Biased sex ratios in plants: theory and trends. The Botanical Review, 78, 63-86.

State Forestry Administration of China (2012) The Saving and Conservation Programme for Extremely Small Populations in China. State Forestry Administration of China, Beijing, China. [In Chinese]

Sun, B.L., ZhanG, C.Q., Lowry, P.P. \& Wen, J. (2009) Cryptic dioecy in Nyssa yunnanensis (Nyssaceae), a Critically Endangered species from tropical Eastern Asia. Annals of the Missouri Botanical Garden, 96, 672-684.

TAO, L.D., HAN, C.Y., SonG, K. \& Sun, W.B. (2020) A tree species with an extremely small population: recategorizing the Critically Endangered Acer yangbiense. Oryx, published online 28 January 2020.

Wu, J.L. \& WU, G.D. (1989) New discovery of Parakmeria omeiensis. Journal of Botany, 2, 4.

XiA, N.H., Liu, Y.H. \& Nоотевоом, H.P. (2008) Magnoliaceae. In Flora of China (eds Z. Wu \& P. Raven), pp. 48-91. Science Press, Beijing, China, \& Missouri Botanical Garden Press, St. Louis, USA.

XU, F.X. (2002) Study on pollen morphology of Parakmeria lotungensis. Guihaia, 22, 157-159.

Yin, H. (2013) The Chinese Higher Plants Red List. Chinese Forestry Press, Beijing, China.

Yu, D.P., LI, C.H., Ding, J., XIE, K.P. \& ZhanG, G.Z. (2011) Preliminary report on character of seed and seed culture in vitro of Parakmeria omeiensis. Resource Develop \& Market, 27, 197-198.

Yu, D.P., LI, C.H., Wen, X.Y., LI, X.J., PENG, Q.X. \& XIE, K.P. (2019) Flowering biology and breeding system of Parakmeria omeiensis. Guihaia, 39, 600-607.

YU, Y.W. \& LIU, X.N. (2013) Influence of global warming to climate tourism resources in Sichuan Province. Journal of Anhui Agricultural Sciences, 41, 7216-7218.

Zhuang, P., Liu, R.Y. \& Liang, K.H. (1993) A preliminary study on phytocoenological characters of Parakmeria omeiensis community. Guihaia, 13, 61-69. 